\title{
25 Research Square \\ The Cost of Community Outreach HIV Interventions in Thailand: A Cohort Study
}

Kyaw Min Soe

Mahidol University

Katharina Hauck

Imperial College London

Sukhum Jiamton

Mahidol University

Sukhontha Kongsin ( $\square$ sukhontha.kon@mahidol.edu )

Mahidol University

\section{Research Article}

Keywords: Cost, Unit Cost, Community-based, HIV intervention, Thailand

Posted Date: September 13th, 2021

DOl: https://doi.org/10.21203/rs.3.rs-688655/v1

License: (a) (i) This work is licensed under a Creative Commons Attribution 4.0 International License. Read Full License 


\section{Abstract \\ Background}

Despite having an estimation of 440000 people living with HIV in 2018, the HIV epidemic in Thailand has become mature and new cases reported have been rapidly declining thanks to its successful prevention programs and scaling up of anti-retroviral therapy (ART). Thailand aimed to achieve its commitment to end the HIV epidemic by 2030 and implemented a cascade of HIV interventions through Reach-Recruit-Test-Treat-Retain (RRTTR) program.

\section{Methods}

This study focused on community-based HIV interventions implemented by Non-Governmental Organizations (NGOs) under RRTTR program in the provinces highly affected by HIV epidemic. We calculated unit cost per person reached for HIV interventions tailored for key-affected populations (KAPs) including men who have sex with men/ transgender (MSM/TG), male sex worker (MSW), female sex worker (FSW), people who inject drug (PWID) and migrant (MW). We studied program outputs, costs, and unit costs in variations across different HIV interventions and geographic locations in Thailand. We used these estimates to evaluate the economies of scale and scope of implementing community-based HIV interventions.

\section{Results}

We analysed a total of 38 community-based HIV interventions in 27 provinces. The average unit cost for a person to received HIV services was 29.7 USD for MSM/TG program, 33.1 USD for MW program, 31.9 USD for FSW program, 36.3 USD for MSW program and 179.1 USD for PWID program. The lowest unit cost per person reached was 21.6 USD for Migrant in Samut Sakhon province while the highest was 324.5 USD for PWID in Samut Prakan. The scattered plots of unit cost per person with polynomial and linear trend line shows the presence of economies of scales.

\section{Conclusions}

This study suggested that community-based HIV interventions led by NGOs in Thailand will only become less costly as they are scaled-up overtime.

\section{Background}

It was estimated that 480000 people were living with HIV in Thailand 2018 and about 15000 people died from AIDS-related illnesses. (1) Nevertheless, the HIV epidemic in Thailand has become mature and new cases reported have been rapidly declining since 1992 thanks to its successful prevention programs along with the scaling up of anti-retroviral therapy (ART). (1) (2) With the aim to achieve its commitment to end the AIDS epidemic by 2030, Thailand has implemented a cascade of HIV interventions through Reach-Recruit-Test-Treat-Retain (RRTTR) program to address the gaps between HIV prevention and life-long treatment system. (2) 
Domestic resources account for more than $85 \%$ of HIV financing and TB responses of Thailand. Although the international funding for HIV was merely a small fraction, it mainly contributed to HIV interventions for non-Thai key-affected populations (KAPs) while majority of domestic funding focused on treatment and care. (3) (4) In 2015, Thailand launched a series of HIV preventive interventions through Reach-Recruit-Test-Treat-Retain (RRTTR) program with the support of the Global Fund which acted as a strategic short-term plan to facilitate the transition of HIV financing to domestic funded disease response by taking into consideration that if the Global Fund investments were to cease. Under this program civil society organizations (CSOs) and non-governmental organizations (NGOs) were contracted as implementing agencies (IAs) for community-based preventive interventions in an active case finding approach to reach out KAPs, created demand for HIV counselling and testing (HCT) with adequate linkages to treatment initiation and retention through collaboration with government health service providers. (5) A total of 38 tailored HIV intervention packages covering the Reach and Recruit components of RRTTR for different KAPs were implemented in 27 provinces with high burden of HIV and TB. HIV prevention services were also integrated with TB services provision for migrant population at the community level. (6)

Since the interventions implemented under RRTTR program were new, yet there are limited empirical evidence regarding the cost, efficiency, and impact of these interventions. It is believed that efficiency gains or cost reductions could be achieved through economies of scale and scope. The former is achieved by cost savings resulting from an increase in scale of operations while the latter by cost reduction through providing jointly services rather than separately. (7)(8) This study aimed at finding evidence for Economies of Scope and Scale. We calculated unit costs per person of tailored HIV intervention packages designed for men who have sex with men (MSM) and transgender people (TG), male sex workers (MSW), female sex workers (FSW), people who inject drugs (PWID), and migrant workers (MW) at the community level which were implemented under this program. We used these estimates to evaluate the economies of scale and scope. The results from this study aimed to provide strategic information for policy makers on setting priorities and optimizing efficiency in resources used for HIV programs within a sustainability financing mechanism when scaling-up.

\section{Methodology}

Research Setting: This study focused on community-based HIV interventions implemented by Non-Governmental Organizations (NGOs) as Implementing agencies (IAs) under RRTTR program in the provinces highly affected by HIV epidemic in Thailand (as shown in Figure 1). This was a cohort study, and the data were collected covering a period of 21 months (from January 2015 to September 2016).

Interventions and Program Activities: Depends on type of targeted KAPs, each intervention package included a combination of 1) behavioral change interventions through outreach activities, harm reduction intervention (for PWID only), distribution of commodities i.e., condoms, lubricants, needles, syringes and behavior change communication (BCC) \& IEC materials etc., 2) HIV testing and counselling, referral to health facilities for HIV testing and/or STI testing, TB screening and testing (Migrant population only), 3) referral to treatment, providing care \& support for those who tested positive, and following up on those who are on ART for treatment adherence, and 4) community health system strengthening.

Peer-led community outreach activities were organized by outreach workers and peer educators who were recruited, trained, and supervised by IAs. Outreach sessions were often provided at a meeting venue in the 
community closed to where KAPs live or work i.e., beauty salons, parks, stadium, universities, local markets, department stores, entertainment venue, public transportation stations, campaign events, beauty contests, and drop-in-centers (DiCs) etc. KAPs were encouraged for HIV testing at the outreach session and those who were willing to get tested will be referred to receive service for Voluntary Confidential Counselling and Testing (VCCT) in collaboration with local government health service providers. VCCT services were often provided at the local public hospital/ health service center, mobile clinic, and community-based HIV testing centers (or DiCs). Outreach workers of SRs provided pre-test and post-test counselling, while HIV testing was done by professional health staffs (nurses and medical technicians) from local government hospitals using pin-prick blood testing with Same Day Result (SDR). It is worth noted that HIV testing and provision of ARV were delivered at the government health facilities, and the cost of which were incurred under the public health system.

Program Outputs: The numbers of KAPs reached out by community-based HIV intervention in the provincial level were defined as the program outputs of in this study. This number included KAPs reached by outreach activities (through individual or group session) and social media (clients registered with unique identification code (UIC) using on-line applications) who received a tailored package of HIV service, participated in behavioral change program, received IEC materials regarding HIV and STI prevention, commodities (such as condom, lubricants, or clean needles \& syringes), counselling services and were referred for HIV/STI testing (for those who were willing to undertake the test). The data were collected from IAs routine reports covering reporting period of January 2015 to September 2016.

\section{Costing Methodology}

This study used top-down costing approach and focuses on health care providers perspective whereas interventions were implemented by IAs at the community level. Patients' costs were not collected and included in this study. We collected data from expenditures records and progress update annual reports of IAs covering expenditures from $1^{\text {st }}$ January 2015 to $30^{\text {th }}$ September 2016 . The data were keyed into excel sheets, pivotal tables were constructed to summarize and calculate unit cost. Shared costs between two or more interventions incurred by the same IAs were allocated proportionally by using different allocation strategies based on type of activities as they were described on records or by looking into program outputs yielded by interventions.

Direct Program Cost (IAs Operational Cost): All cost incurred at site (provincial) level or IAs level were defined as Direct Program Cost. Costs were disaggregated into different level, firstly by program areas then by interventions, activities, and cost inputs. Shared cost across different KAPs or program area were allocated accordingly using allocation criterion based on their program outputs.

The cost included both recurrent and capital costs utilized by IAs which were reported into 13 cost inputs; Human Resources (HR), Travel related costs (TRC), External Professional services (EPS), Health Products Pharmaceutical Products (HPPP), Health Products - Non-Pharmaceuticals (HPNP), Health Products - Equipment (HPE) including HIV test kit, Procurement and Supply-Chain Management costs (PSM), Infrastructure (INF), Nonhealth equipment (NHE), Communication Material and Publications (CMP), Indirect and Overhead Costs, and Living support to client/ target population (LSCTP).

Indirect Program Cost (Overhead cost): At above site level, overhead costs (include program management, health system strengthening, monitoring and evaluation etc.) were calculated and allocated accordingly to all 15 IAs 
who received funding through primary recipient (PR) agency who received funding through the Global Fund program.

Unit Cost: We calculated unit cost per targeted KAP reached by a community-based HIV intervention or unit cost per person to receive service from a community-based HIV intervention. The unit cost was defined as total cost divided by total program outputs. The unit cost at IAs level was first calculated by allocating all direct program cost (operational cost) at site level while excluding overhead cost. The unit costs including both direct program cost and overhead cost from above IAs level were then calculated. The overhead costs were allocated proportionally to IAs' individual intervention by using allocation strategies based on each intervention program outputs.

\section{Table 1: Characteristics of community outreach HIV interventions in this study}




\begin{tabular}{|c|c|c|}
\hline Characteristics & Number & $\%$ \\
\hline No. of Implementing Agencies (IAs) & 20 & \\
\hline No. of Provinces covered & 27 & \\
\hline No. of HIV intervention Package Delivered & 38 & \\
\hline No. of TB intervention Package Delivered & 7 & \\
\hline Total Cost spent for all intervention programs (USD) & 9473316 & \\
\hline - Cost for HIV interventions (USD) & 7837234 & $(82.7 \%)$ \\
\hline - Cost for TB interventions (USD) & 1636082 & $(12.3 \%)$ \\
\hline - Total Direct Program Cost by IAs (USD) & 6686157 & $(70.6 \%)$ \\
\hline - Total Indirect Program Cost or overhead cost (USD) & 2787160 & $(29.4 \%)$ \\
\hline \multicolumn{3}{|l|}{ HIV Intervention Package } \\
\hline \multicolumn{3}{|l|}{ 1. Cost spent by IAs for HIV interventions (USD) } \\
\hline - Direct Program Cost by IAs & 5576092 & $(71.1 \%)$ \\
\hline - Overhead Cost above IAs level & 2261142 & $(28.9 \%)$ \\
\hline - Mean Cost & 146739 & \\
\hline - Min. Cost & 31122 & \\
\hline - Max. Cost & 294562 & \\
\hline - Standard Deviation & 104474 & \\
\hline \multicolumn{3}{|c|}{ 2. No. of Targeted KAP reached by HIV Interventions (Person) } \\
\hline - Total persons reached & 190931 & \\
\hline - Mean & 5025 & \\
\hline - Minimum & 161 & \\
\hline \multirow[t]{2}{*}{ - Maximum } & 25438 & \\
\hline & 5367 & \\
\hline
\end{tabular}


- Standard Deviation

3. No. of Targeted KAP received HIV tests (Person)

- Total No. of targets tested

32309

850

- Mean

20

- Minimum

1548

- Maximum

936

- Standard Deviation

TB Intervention Package

4. Cost spent by IAs for TB interventions (USD)

- Total Cost (Direct Program Cost)

1110065

- Total No. of targets reached (Person)

56099

878

- Total No. of TB suspect found (Person)

\section{Results}

This study identified 45 community-based HIV/TB interventions (38 HIV interventions and 8 TB interventions) delivered by IAs to KAPs in 27 provinces of Thailand. Among 38 HIV interventions, there were 14 interventions targeting MSM/TG population, 12 harm reduction interventions for PWID and their partners, 7 interventions for migrant workers, and 5 interventions for sex workers (4 MSW and $1 \mathrm{FSW}$ ) and their clients. All TB interventions program were focused on migrant workers (Table 1).

\section{Program Outputs}

All community-based HIV interventions combined had reached out and delivered services to a total of 190931 targeted KAPs after its first 21 months of launching. This number included 98561 (51.6\%) of MSM/TG, 41636 (21.8\%) MW, 25260 (13.2\%) MSW, 13308 (7\%) FSW, and 12166 (6.4\%) PWID. Average number of targeted population reached by a harm reduction (PWID) intervention was 1014 and was significantly lower than that of other interventions focus on MSW/FSW (7714), MSM/TG (7040) and MW (5948).

The prevention program for MSM/TG in Bangkok alone contributed to the highest number in terms of targets reached by a single intervention program having $25438 \mathrm{MSM} / \mathrm{TG}$ received services, while prevention program for PWID in Satun province achieved the lowest targets by 161 PWID received services (Table 2). Average number of targets reached by any intervention was 5025 KAPs. Among all KAPs reached out by interventions, 32309 were 
referred to tested through HIV counselling and testing services. The highest number of HIV tests referred by a single intervention was achieved in Chiang Mai whereas 4179 MSM/TG were tested followed by the intervention in Bangkok of 4076 MSM/TG tested. The lowest number of tested was recorded in Samut Prakan intervention for PWID which has only 20 of PWID tested for HIV. In case of TB interventions, a total of 56099 migrants were reached and 878 TB suspects were identified and referred for TB confirmation to local hospitals for further arrangement.

\section{Cost}

The total cost of all 45 community-based outreach interventions was 9473316 USD from January 2015 to September 2016 whereas 82.7\% (7837234 USD) were spent for HIV interventions and the rest of $12.3 \%$ (1636082 USD) for TB interventions. It comprised Direct Program Cost (Operational Cost) 6686157 USD (70.6\%) by Implementing Agencies (IAs) at the site level and Indirect Program Cost or Overhead Cost 2787160 USD (29.4\%) incurred at above IAs level (Table 3).

HIV interventions cost could be further divided into direct program cost 5576092 USD (71.1\%) at IAs level and overhead cost or Indirect Program Cost 2261142 USD (28.9\%) above IAs level. Without including overhead costs, the cost for $14 \mathrm{MSM} / \mathrm{TG}$ interventions was 1775546 USD, 4 MSW interventions 668854 USD, 1 FSW intervention 294562 USD, 14 PWID interventions 1958613 USD, and 6 MW interventions 878518 USD, respectively. After adding up overhead costs, the total cost for MSM interventions was 2929664 USD, MSW 918065 USD, FSW 424937 USD, PWID 2186047 USD, and MW 1378521 USD, respectively (Table 3). 
Table 2

Cost, outputs, and unit cost of HIV interventions in different provinces from January 2015 to September 2016

\begin{tabular}{|c|c|c|c|c|}
\hline Provinces & Interventions & Cost (USD) & Outputs (Persons) & $\begin{array}{l}\text { Unit } \\
\text { Cost } \\
\text { (USD } \\
\text { per } \\
\text { person) }\end{array}$ \\
\hline
\end{tabular}

\begin{tabular}{|c|c|c|c|c|c|c|c|c|}
\hline & $\begin{array}{l}\text { Direct } \\
\text { Program } \\
\text { Cost }\end{array}$ & $\begin{array}{l}\text { IPC } \\
\text { (Overhead) }\end{array}$ & Total & Reached & Tested & $\begin{array}{l}\text { Reached } \\
\text { (Excl. } \\
\text { IPC) }\end{array}$ & $\begin{array}{l}\text { Reached } \\
\text { (Incl. } \\
\text { IPC) }\end{array}$ & \\
\hline Bangkok & FSW & 294562 & 130376 & 424937 & 13308 & 1548 & 22.1 & 31.9 \\
\hline Chiang Mai & Migrants & 191020 & 92533 & 283553 & 5215 & 1228 & 36.6 & 54.4 \\
\hline Chon Buri & Migrants & 75779 & 35454 & 111233 & 2966 & 425 & 25.5 & 37.5 \\
\hline Rayong & Migrants & 124736 & 61036 & 185772 & 4740 & 970 & 26.3 & 39.2 \\
\hline $\begin{array}{l}\text { Samut } \\
\text { Prakan }\end{array}$ & Migrants & 93261 & 77535 & 170796 & 7369 & 743 & 12.7 & 23.2 \\
\hline $\begin{array}{l}\text { Samut } \\
\text { Sakhon }\end{array}$ & Migrants & 182912 & 180886 & 363798 & 16881 & 1515 & 10.8 & 21.6 \\
\hline Songkhla & Migrants & 152667 & 33718 & 186385 & 2727 & 613 & 56.0 & 68.3 \\
\hline Trat & Migrants & 58144 & 18842 & 76985 & 1738 & 229 & 33.5 & 44.3 \\
\hline Bangkok & MSM/TG & 444216 & 294597 & 738813 & 25438 & 4046 & 17.5 & 29.0 \\
\hline Chiang Mai & $\mathrm{MSM} / \mathrm{TG}$ & 204023 & 178388 & 382411 & 13757 & 4179 & 14.8 & 27.8 \\
\hline Chon Buri & MSM/TG & 88494 & 61233 & 149727 & 5599 & 744 & 15.8 & 26.7 \\
\hline Khon Kaen & MSM/TG & 136715 & 72900 & 209616 & 6480 & 1473 & 21.1 & 32.3 \\
\hline $\begin{array}{l}\text { Nakhon } \\
\text { Ratchasima }\end{array}$ & MSM/TG & 101277 & 57128 & 158406 & 5101 & 1079 & 19.9 & 31.1 \\
\hline $\begin{array}{l}\text { Nakhon Si } \\
\text { Thammarat }\end{array}$ & MSM/TG & 162830 & 82147 & 244977 & 7176 & 2176 & 22.7 & 34.1 \\
\hline Nonthaburi & MSM/TG & 67998 & 52984 & 120983 & 4542 & 539 & 15.0 & 26.6 \\
\hline $\begin{array}{l}\text { Pathum } \\
\text { Thani }\end{array}$ & MSM/TG & 62759 & 47020 & 109779 & 4138 & 709 & 15.2 & 26.5 \\
\hline Phuket & MSM/TG & 68036 & 43753 & 111788 & 3842 & 1017 & 17.7 & 29.1 \\
\hline $\begin{array}{l}\text { Samut } \\
\text { Prakan }\end{array}$ & MSM/TG & 101022 & 71244 & 172266 & 6206 & 643 & 16.3 & 27.8 \\
\hline Songkhla & MSM/TG & 121482 & 82958 & 204440 & 6845 & 936 & 17.7 & 29.9 \\
\hline Surat Thani & MSM/TG & 71528 & 26204 & 97732 & 2285 & 235 & 31.3 & 42.8 \\
\hline
\end{tabular}

Note: KAPs (Key Affected Population), IAs (Implementing Agencies), IPC (Indirect Program Cost), Excl (Exclude), Incl (Include), FSW (Female sex workers), MSM/TG (Men who have sex with men/ Transgender), MSW (Male Sex Worker), PWID (People who inject drug). 


\begin{tabular}{|c|c|c|c|c|c|c|c|c|}
\hline \multicolumn{2}{|l|}{ Provinces } & \multirow{2}{*}{$\begin{array}{l}\text { Interventions } \\
\begin{array}{l}\text { IPC } \\
\text { (Overhead) }\end{array}\end{array}$} & \multicolumn{3}{|c|}{ Cost (USD) } & \multicolumn{2}{|c|}{ Outputs (Persons) } & \multirow{2}{*}{$\begin{array}{l}\text { Unit } \\
\text { Cost } \\
\text { (USD } \\
\text { per } \\
\text { person) }\end{array}$} \\
\hline & $\begin{array}{l}\text { Direct } \\
\text { Program } \\
\text { Cost }\end{array}$ & & Total & Reached & Tested & $\begin{array}{l}\text { Reached } \\
\text { (Excl. } \\
\text { IPC) }\end{array}$ & $\begin{array}{l}\text { Reached } \\
\text { (Incl. } \\
\text { IPC) }\end{array}$ & \\
\hline $\begin{array}{l}\text { Ubon } \\
\text { Ratchathani }\end{array}$ & MSM/TG & 44872 & 28022 & 72894 & 2430 & 391 & 18.5 & 30.0 \\
\hline Udon Thani & MSM/TG & 100294 & 55541 & 155835 & 4722 & 649 & 21.2 & 33.0 \\
\hline Bangkok & MSW & 318508 & 127734 & 446241 & 14528 & 1435 & 21.9 & 30.7 \\
\hline Chiang Mai & MSW & 103077 & 32039 & 135115 & 3268 & 988 & 31.5 & 41.3 \\
\hline Chon Buri & MSW & 147453 & 76362 & 223815 & 6131 & 1242 & 24.1 & 36.5 \\
\hline Phuket & MSW & 99817 & 13076 & 112893 & 1333 & 470 & 74.9 & 84.7 \\
\hline Bangkok & PWID & 382652 & 41909 & 424561 & 2181 & 235 & 175.4 & 194.7 \\
\hline Chiang Mai & PWID & 361299 & 40903 & 402202 & 2276 & 535 & 158.7 & 176.7 \\
\hline Chiang Rai & PWID & 92040 & 9090 & 101130 & 573 & 69 & 160.6 & 176.5 \\
\hline Narthiwat & PWID & 346993 & 48496 & 395488 & 2463 & 296 & 140.9 & 160.6 \\
\hline Pattani & PWID & 102864 & 12187 & 115051 & 655 & 129 & 157.0 & 175.7 \\
\hline Phatthalung & PWID & 47998 & 4886 & 52884 & 270 & 45 & 177.8 & 195.9 \\
\hline $\begin{array}{l}\text { Samut } \\
\text { Prakan }\end{array}$ & PWID & 80086 & 4016 & 84102 & 247 & 20 & 324.2 & 340.5 \\
\hline Satun & PWID & 31122 & 2765 & 33887 & 161 & 67 & 193.3 & 210.5 \\
\hline Songkhla & PWID & 111541 & 16614 & 128155 & 803 & 166 & 138.9 & 159.6 \\
\hline Tak & PWID & 233059 & 24564 & 257623 & 1452 & 174 & 160.5 & 177.4 \\
\hline Trang & PWID & 93988 & 9903 & 103891 & 565 & 317 & 166.3 & 183.9 \\
\hline Yala & PWID & 74972 & 12102 & 87074 & 520 & 34 & 144.2 & 167.4 \\
\hline
\end{tabular}

\section{Unit Cost}

The average unit cost (with the inclusion of program cost while excluding overhead cost or indirect program cost) for a KAP to received HIV services delivered by IAs was 18 USD per person reached for MSM/TG, 21.1 USD per person reached for MW, 22.1 USD per person reached for FSW, 26.5 USD per person reached for MSW, and 161 
USD per person reached for PWID (Table 3). The lowest unit cost per person reached was 10.8 USD for Migrant in Samut Sakhon province while the highest was 324.5 per person reached for PWID in Samut Prakan (Table 2).

After inclusion of overhead cost (Indirect Program Cost) at above site level into calculation, average unit cost was 29.7 USD per person reached for MSM/TG, 33.1 USD per person reached for MW, 31.9 USD per person reached for FSW, 36.3 USD per person reached for MSW, and 179.1 USD per person reached for PWID (Table 3). Migrant intervention in Samut Sakhon remained as the intervention with the lowest unit cost (21.6 USD per person reached) despite about $50 \%$ increased after adding up overhead cost. PWID intervention in Samut Prakan remained the one with the highest unit cost (340.5 USD per person reached) with merely $5 \%$ increase after adding up the overhead cost (Table 2).

The unit cost per person to received tailored HIV intervention package were put in scattered plots with both polynomial and linear trend lines to identify potential evidence of economies of scales. Interestingly, the result shows the presence of economies of scales. This indicates that the higher number of KAPs reached by community-based HIV interventions, the lower they will cost.

Table 3

Cost, inputs, outputs, and average unit cost of HIV interventions among different key affective populations

\begin{tabular}{|c|c|c|c|c|c|c|c|c|}
\hline \multirow[t]{2}{*}{$\begin{array}{l}\text { HIV } \\
\text { Interventions }\end{array}$} & \multirow[t]{2}{*}{ No. } & \multicolumn{3}{|c|}{ Inputs/Cost (USD) } & \multicolumn{2}{|c|}{ Outputs (Persons) } & \multicolumn{2}{|c|}{$\begin{array}{l}\text { Average unit cost } \\
\text { (USD per person) }\end{array}$} \\
\hline & & $\begin{array}{l}\text { Program } \\
\text { Cost }\end{array}$ & $\begin{array}{l}\text { IPC } \\
\text { (Overhead) }\end{array}$ & Total & Reached & Tested & $\begin{array}{l}\text { Reached } \\
\text { (Ex. IPC) }\end{array}$ & $\begin{array}{l}\text { Reached } \\
\text { (In. IPC) }\end{array}$ \\
\hline MSM/TG & 14 & 1775546 & 1154119 & 2929664 & 98561 & 18816 & 18.0 & 29.7 \\
\hline MSW & 4 & 668854 & 249211 & 918065 & 25260 & 4135 & 26.5 & 36.3 \\
\hline FSW & 1 & 294562 & 130376 & 424937 & 13308 & 1548 & 22.1 & 31.9 \\
\hline PWID & 12 & 1958613 & 227434 & 2186047 & 12166 & 2087 & 161.0 & 179.7 \\
\hline Migrant & 7 & 878518 & 500003 & 1378521 & 41636 & 5723 & 21.1 & 33.1 \\
\hline Total & 38 & 5576092 & 2261141 & 7837234 & 190931 & 32309 & 29.2 & 41.0 \\
\hline \multicolumn{9}{|c|}{$\begin{array}{l}\text { Note: KAPs (key affected populations), IPC (Indirect Program Cost), Ex. (Exclude), In. (Include), FSW (Female } \\
\text { sex workers), MSM/TTG (Men who have sex with men/ Transgender), MSW (Male Sex Worker), PWID (People } \\
\text { who inject drug). }\end{array}$} \\
\hline
\end{tabular}

\section{Discussion}

Thailand has achieved the first and third 90s of UNAIDS' $90-90-90$ targets in 2018 whereas more than $90 \%$ of people living with HIV in Thailand were aware of their status and of those $80 \%$ were on treatment thanks to its successful HIV prevention, testing and treatment programs. (1) As the country HIV epidemic is mature and concentrated in KAPs, its approach of targeting population who were at the highest risk in highly priority geographical sites appeared to be both feasible and effective. The results in this study show that communitybased outreached interventions led by NGOs and CSOs were critical in Thailand's new approach for fighting 
against the epidemic. Community-based HIV interventions has reached out a significant number of KAPs in high priority geographical sites and brought them into HIV prevention and life-long treatment system under RRTTR program.

We found that unit cost per person reached by HIV intervention package varies across targeted populations and geographical areas in Thailand. Average unit cost per person of an intervention package for MSM/TG was the lowest followed by interventions for MW, MSW, FSW, and PWID, respectively. In Thailand, HIV prevention services led by NGOs in partnership with public health facilities for MSM/TG and other KAPs were available countrywide prior to RRTTR program especially in large cities and tourist destinations where MSM/TGs were concentrated. (2) (5) (9) (10) Some IAs were, therefore, able to adapt new HIV intervention programs into their existing programs rather than creating new implementing structures and plans. As a result, this might have reduced start-up cost and increased the efficiency of interventions. (7) Average unit cost of an intervention for PWID was found five folds higher compare to other HIV interventions. In addition, this study found very low uptake among HIV intervention services for PWID which suggested that intervention for PWID were less viable compared to interventions focusing on other KAPs. There were studies indicated that policy and legal constraints has displaced many PWID access to lifesaving healthcare services in Thailand. Fear of disclosure, Stigma and discrimination in healthcare settings and concerns over confidentiality were among main factors which causes low demand in HIV services for PWID. (11) (12) (13) Therefore, the uptake of services was often low and more intensive service delivery with comprehensive package was needed in reaching out these PWID population. Unit costs for HIV intervention for MW in Samut Prakan and Samut Sakhon were the lowest among all interventions. It is noteworthy that HIV and TB prevention services were integrated and implemented simultaneously to MW by the same IAs under RRTTR program. There is a possible cause of economy of scope observed here whereas IAs were able to distribute fixed cost for reaching out more cases from both HIV and TB interventions. In addition, sharing of services could reduce input prices and task shifting could lead to greater efficiency through integrated services. (7) (14) However, there are some contextual factors should be considered when we interpret the trend of unit costs of HIV interventions which include IAs' program maturity, geographic structural factors (i.e., how difficult or ease to physically access the location), quality of services provided and efficiency of service delivery etc. For instance, program immaturity is likely associated with high start-up cost for new service or location and insufficient service delivery process. And higher quality services with relatively more comprehensive care or package is likely to result in higher unit cost and low targeted reached. (15) (16)

We found efficiency increased across full range of scales examined among HIV interventions led by community based IAs in Thailand. The cost per key outputs (cost per person reached) and scale are found to be correlated negatively (Fig. 2). Despite the presence of up-turn point for cost per person reached (Fig. 2), it is merely due to one data point. And it is noteworthy that regression trends were downward sloping in both cases with simple liner function. Therefore, even though we only observed unit costs of interventions for a period of 21 months, this study suggested that community outreach HIV interventions will only become less costly overtime after scaling up. (8) (17)

In addition, we calculated unit cost by allocating overhead costs using different cost allocation ratios (i.e., according to the size of targeted KAPs in the implementing province and the amount of grants/funding that IAs received to implement interventions) as sensitivity analysis and the trends are shown in Fig. 3.

Page $12 / 18$ 
Nevertheless, this research study is subject to some potential limitations that could be addressed in future studies. All interventions led by CSOs under this program was initially intended to be lasted for two years. However, it was later extended for another two years. At the time of data collection for this study, we were only able to collect data covered the first 21 months periods after its initial implementation. This study applies only the cost of HIV services provided at the community level which does not include the cost incurred from patients' perspective. Due to limitations of the secondary data, this study does not investigate potential contextual factors that might act as cost drivers for interventions and discuss whether the same results, or better results might have been achieved with greater efficiency. The cost and efficiency of TB prevention services integrated with HIV services to MW should be evaluated and discussed along with HIV services in further studies. In addition, other components of RRTTR (i.e., testing and provision of treatment under conventional public health system etc.) should also be evaluated in future studies.

\section{Conclusion}

This study suggested that community outreach HIV interventions led by CSOs in Thailand will only become less costly as they are scaled up overtime. The integration of HIV prevention services with TB prevention services may also reduce costs. Further studies are required to follow up with this ongoing intervention programs in depth to determine how to improve efficiency of HIV prevention services in Thailand.

\section{Abbreviations}

HIV

human immuno-deficiency virus, ART:anti-retroviral therapy, RRTTR:Reach-Recruit-Test-Treat-Retain program, NGOs:Non-Governmental Organizations, CSOs:civil society organizations, KAPs:key-affected populations, MSM/TG:men who have sex with men/ transgender, MSW:male sex worker, FSW:female sex worker, PWID:people who inject drug, MW:migrant worker, IAs:Implementing agencies, DiCs:drop-in-centers, VCCT:Voluntary Confidential Counselling and Testing.

\section{Declarations}

\section{Ethical Approval}

The study applied secondary data collected by Research Centre for Health Economics and Evaluation, Faculty of Public Health, Mahidol University which was used for the study title on "Evaluation on Stop TB and AIDS through

Reach-Recruit-Test-Treat-Retain: STAR-NFM. It was approved by Ethical Reviewing Committee, Faculty of Public Health, Mahidol University, Thailand (COA. No. MUPH 2017-172

\section{Consent to publish}

Not applicable.

\section{Availability of data and materials}

The datasets used and/or analyzed during the current study are available from the corresponding author on reasonable request. 


\section{Competing interests}

The authors declare that they have no competing interests.

\section{Funding}

This research study was funded by the Wellcome Trust through Global Health Clinical Research Training Fellowship Program (sponsor reference ID 204834/Z/16/Z and award No. RSRO_P67869). The funder provided financial support for the first author to undertake his fellowship training program at the Department of Infectious Disease Epidemiology, Imperial College. The support included his salary, accommodation, and travel expenses for meeting with oversea advisors and data collection to complete this project.

\section{Authors' contributions}

KMS is responsible for the conception and design of the study, analysis and interpretation of the data, and writing. $\mathrm{KH}$ is responsible for the design of the study, analysis, and the interpretation of the data. SJ and SK are responsible for the design of the study, data collection and analysis, and the interpretation of the data. The authors read and approved the final manuscript.

\section{Acknowledgements}

Not applicable

\section{References}

1. The Joint United Nations Programme on HIV/AIDS (UNAIDS). AIDS DATA. 2019.

2. National AIDS Committee Thailand (NAC). Thailand AIDS Response Progress Report. 2014.

3. Patcharanarumol, W., Thammatacharee, N., Kittidilokkul, S. et al. Thailand's HIV/AIDS program after weaningoff the global fund's support. BMC Public Health 13, 1008 (2013). https://doi.org/10.1186/1471-2458-131008.

4. The Joint United Nations Programme on HIV/AIDS (UNAIDS). Country Snapshot, Thailand. 2018.

5. National AIDS Committee Thailand (NAC). Thailand National Operational Plan 2015-2019. Nonthaburi: 2014.

6. The Global Fund. Grant Agreement on Stop TB and AIDS through RRTTR (STAR) Thailand. 2015. https://data.theglobalfund.org/investments/grant/THA-C-RTF/. Accessed April 2020.

7. Mariana S, Michelle R, Carol DO, Claudia BM, Karl LD, Anna V. Is there scope for cost savings and efficiency gains in HIV services? A systematic review of the evidence from low- and middle-income countries. Bulletin of the World Health Organization. 2014; 92(7): 499-511AD. https://doi.org/10.2471/BLT.13.127639.

8. Carol DO, Lorna G, Sedona S, Integra I, Anna V. Does integration of HIV and SRH services achieve economies of scale and scope in practice? A cost function analysis of the Integra Initiative. Sexually transmitted infections, 92(2). 2016: 130-134. http://dx.doi.org/10.1136/sextrans-2015-052039.

9. Wolf RC. Thailand global fund round 8 external evaluation: men who have sex with men (MSM). 2012. Available at: . Accessed April 2020. 
10. Taweesap S, Sumet O, Patchara B, Wiwat P, Sharma M. The impact of Thailand's public health response to the HIV epidemic 1984-2015: understanding the ingredients of success. Journal of Virus Eradication. 2016 November 28; 2 Suppl 4: 7-14.

11. Ti L, Kaplan K, Hayashi K, Suwannawong P, Wood E, Kerr T. Low rates of hepatitis C testing among people who inject drugs in Thailand: implications for peer-based interventions. Journal of Public Health. 2013 December; 35(4): 578-584. https://doi.org/10.1093/pubmed/fds105.

12. Churcher S. Stigma related to HIV and AIDS as a barrier to accessing health care in Thailand: a review of recent literature. WHO South East Asia J Public Health. 2013 Jan-Mar; 2(1): 12-22. https://doi.org/10.4103/2224-3151.115829.

13. Kanna H, Will S, Joanne C, Sattara H, Thomas K. Experiences with Policing among People Who Inject Drugs in Bangkok, Thailand: A Qualitative Study. Plos Medicine. 2013 December 10; 10(12). https://doi.org/10.1371/journal.pmed.1001570.

14. Omar Gr, Richard G, Sandra GSR, Mercy GM, David CL, Sergio BA, et al. HIV prevention costs and their predictors: evidence from the ORPHEA Project in Kenya. Health Policy and Planning. 2017 September 26; 32(10): 1407-1416. https://doi.org/10.1093/heapol/czx121.

15. Chandrashekar S. Scaling up HIV/AIDS prevention in India: an economic analysis of Avahan interventions for high-risk groups in four southern states. MPhil thesis, London School of Hygiene \& Tropical Medicine. 2015. http://dx.doi.org/10.17037/PUBS.02997235.

16. Sergio BA, Gina LHF, David CL, Ada K, S. Janae VB, Ogbonna OA, et al. Efficiency of HIV services in Nigeria: Determinants of unit cost variation of HIV counseling and testing and prevention of mother-to-child transmission interventions. Plos One. 2018 September 7; 13(9). https://doi.org/10.1371/journal.pone.0201706.

17. Marseille, E., Dandona, L., Marshall, N. et al. HIV prevention costs and program scale: data from the PANCEA project in five low and middle-income countries. BMC Health Serv Res 7, 108 (2007). https://doi.org/10.1186/1472-6963-7-108.

\section{Figures}




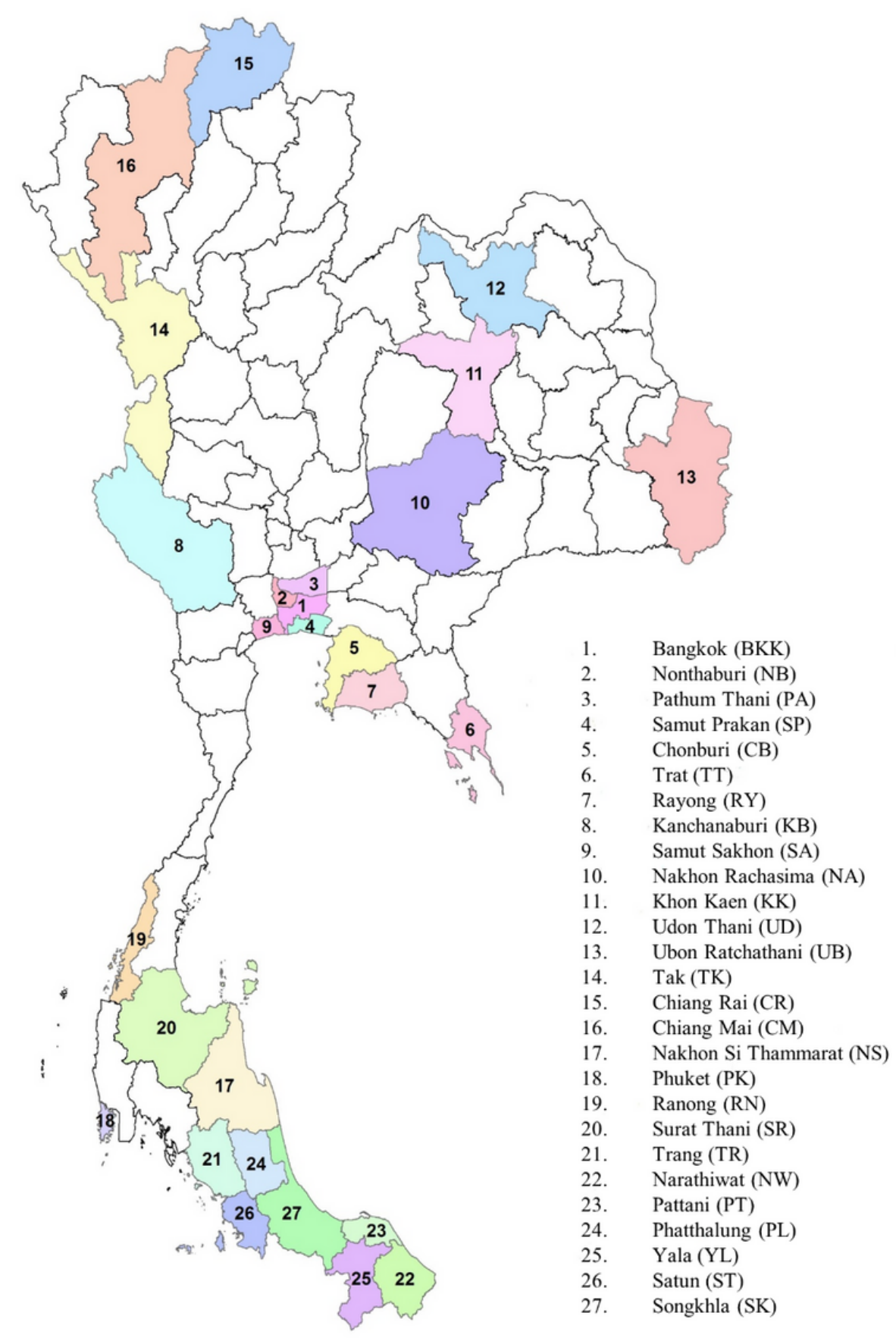

Figure 1

Provinces highly affected by HIV and TB disease burden in Thailand 


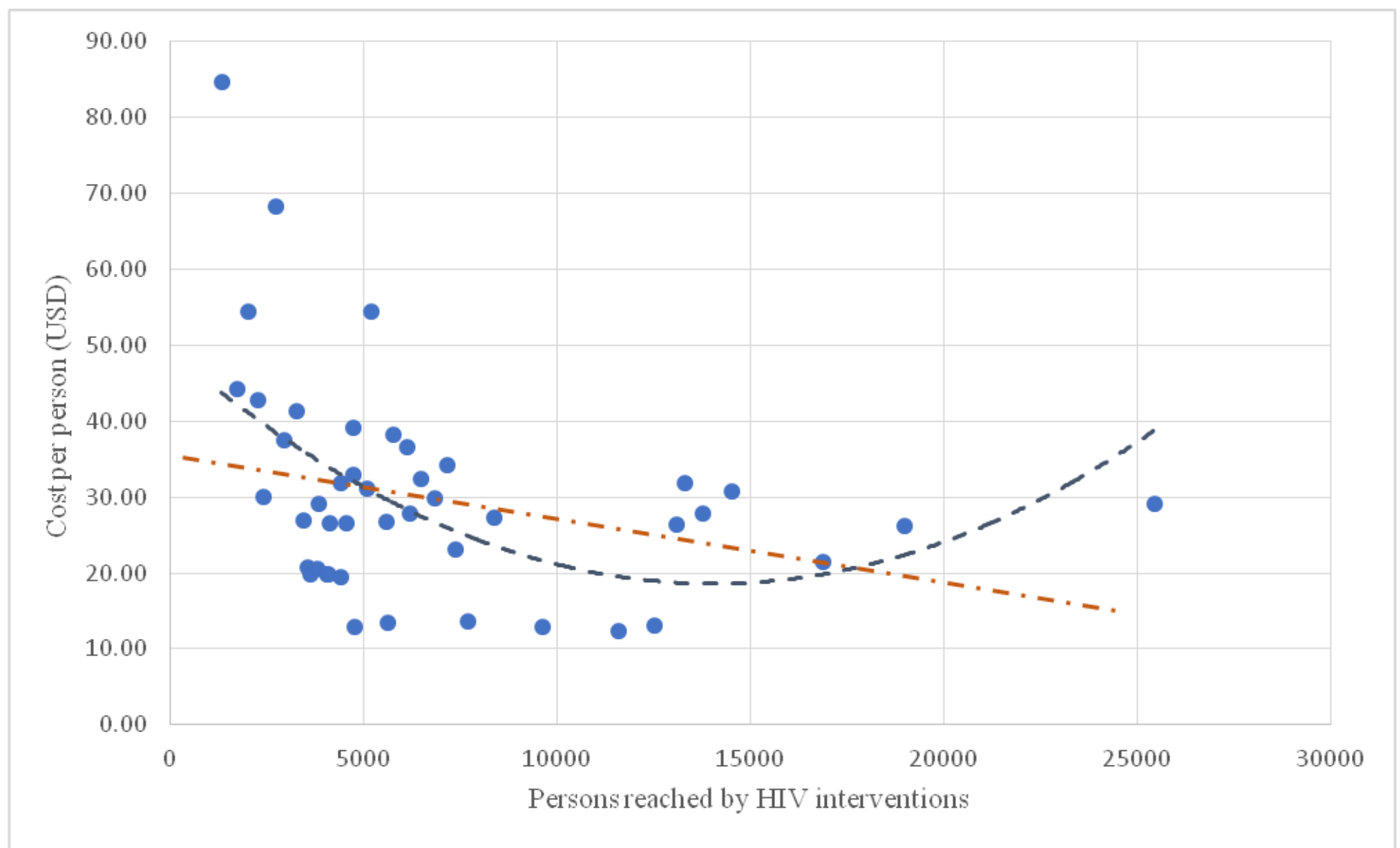

Figure 2

Cost per person reached vs scale of HIV interventions with Linear and Polynomial trend line 


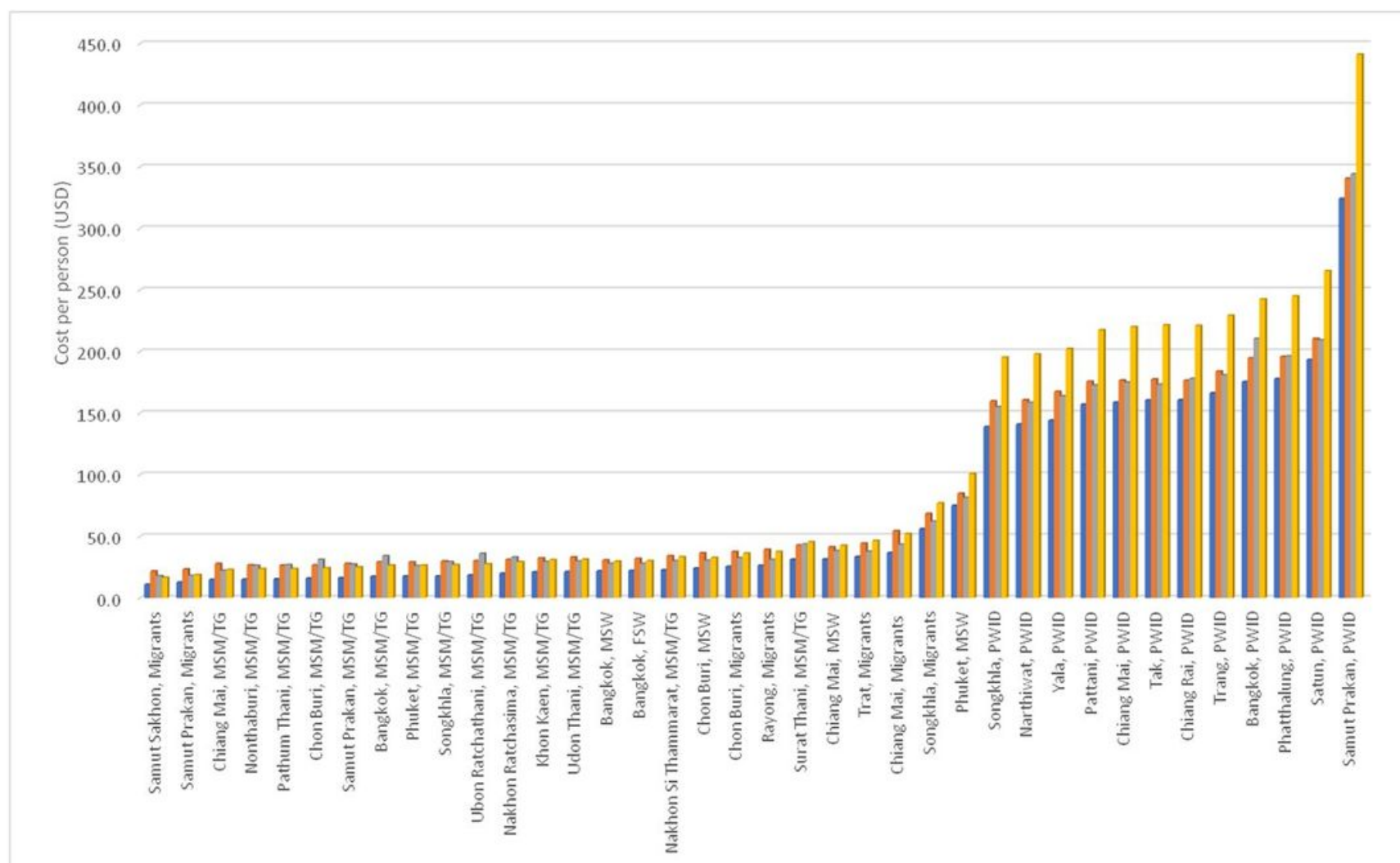

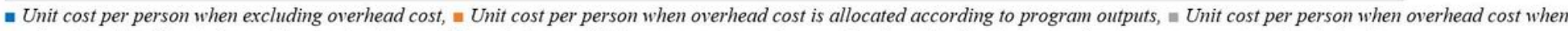
overhead cost is allocated according to size of targeted populations, =Unit cost per person when overhead cost is allocated according to program cost at the site level.

Note: FSW (Female sex workers), MSM/TG (Men who have sex with men/ Transgender), MSW (Male Sex Worker), PWID (People who inject drug).

\section{Figure 3}

Unit cost per person reached by HIV intervention using different allocation strategies over overhead cost 